\title{
Object manipulability affects children's and adults' conceptual processing
}

\author{
Solène Kalénine and FranÇOISE BonthouX \\ LPNC, CNRS UMR 5105, Université Pierre Mendès-France, Grenoble, France
}

\begin{abstract}
Research on kinds of concepts indicates that children use perceptual and functional information differently to form natural and artifact concepts. Beyond object domain, object manipulability appears to be a decisive factor in adult conceptual processing. Thus, the effect of object manipulability on conceptual processing was tested in 5- and 7-year-olds and adults using a picture matching task. Reaction times for identifying conceptual relations on the basis of perceptual similarity (e.g., jacket-coat) and contextual/functional information (e.g., jacket-hanger) were analyzed according to object manipulability and domain. Both children and adults were faster to identify contextual/functional relations for manipulable than for nonmanipulable objects. Conversely, they were faster to identify perceptual similarity relations for nonmanipulable than for manipulable objects, particularly for natural concepts. Results reveal an early distinction between concepts of manipulable and nonmanipulable objects. Implications for further research on concept formation and for embodied views of concepts are discussed.
\end{abstract}

A large body of evidence from developmental psychology, cognitive psychology, and neuropsychology supports the idea that there are different kinds of concepts. Artifact concepts would be mostly characterized by function, whereas natural kinds would be predominantly organized around perceptual information. Numerous studies in children show that functional similarities drive induction, name generalization, and categorization for artifacts from age 2 at the latest (Casler \& Kelemen, 2007; Diesendruck, Markson, \& Bloom, 2003; Kemler Nelson, Chan Egan, \& Holt, 2004; Kemler Nelson, Russell, Duke, \& Jones, 2000; Truxaw, Krasnow, Woods, \& German, 2006). On the contrary, children often rely on perceptual similarity to categorize natural kinds (Sloutsky, Kloos, \& Fisher, 2007; Sloutsky \& Spino, 2004). Moreover, data from property generation tasks in normal adults (Cree \& McRae, 2003; McRae, Cree, Seidenberg, \& McNorgan, 2005) and children (Hughes, Woodcock, \& Funnell, 2005) demonstrated that perceptual/visual features are more important for natural kinds, whereas contextual/functional features are more crucial for artifacts. This dissociation is also well documented in neuropsychology, with reports of semantic deficits specific to natural kinds or artifacts (for a review, see Capitani, Laiacona, Mahon, \& Caramazza, 2003). On the whole, these findings indicate that different conceptual mechanisms may underlie natural kind and artifact concepts, based on the detection of perceptual and functional similarities, respectively.

However, the distinction between natural kind and artifact concepts does not appear so clear-cut. Recently, the importance of function has also been generalized to natural concepts (DiYanni \& Kelemen, 2005; Kelemen \& Di-
Yanni, 2005). In the same way, the influence of perceptual similarity does not seem restricted to natural kinds and has also been observed for artifacts (Diesendruck \& Bloom, 2003; Diesendruck, Hammer, \& Catz, 2003). Since internal and functional features usually determine superficial ones (Ahn, Gelman, Amsterlaw, Hohenstein, \& Kalish, 2000), perceptual properties can heuristically be good cues to categorize both natural objects and artifacts. Moreover, category-specific deficits in brain-damaged patients do not systematically follow the living/nonliving dissociation (Capitani et al., 2003). These findings suggest that functional and perceptual similarities are important cues for both natural kind and artifact concept formation.

Furthermore, a finer distinction between manipulable and nonmanipulable object concepts may be considered in the light of recent work on conceptual processing, mainly in adults. Findings from property verification (Borghi, 2004; Marques, 2006; Pecher, Zeelenberg, \& Barsalou, 2003, 2004) and language comprehension (Stanfield \& Zwaan, 2001; Zwaan, Stanfield, \& Yaxley, 2002) seem to indicate that adults reactivate their sensorimotor experience with objects when processing concepts (Barsalou, 1999, 2008). Consequently, manipulable objects would give rise to specific conceptual processing, since they strongly involve motor experience. Manipulation priming has been observed for manipulable objects - for example, "piano" primed "typewriter" (Myung, Blumstein, \& Sedivy, 2006). Tucker and Ellis (2004) also reported affordance compatibility effects - such as shorter reaction times (RTs) when the response grip was congruent with the action afforded by the presented object - for manipulable objects, either natural objects or artifacts. In a recent

S. Kalénine, solene.kalenine@upmf-grenoble.fr 
developmental study, Mounoud, Duscherer, Moy, and Perraudin (2007) have shown that identification and categorization of tools by 7 - and 9-year-olds are facilitated by the previous presentation of their corresponding action pantomime. In addition, data from neuroimagery show that tool conceptual processing specifically activates those cerebral areas involved in object manipulation - that is, the parietal and premotor cortices (Chao \& Martin, 2000; Gerlach, Law, \& Paulson, 2002; Kellenbach, Brett, \& Patterson, 2003). On the contrary, animate concepts mostly activate the visual system - that is, the temporo-occipital cortex (for a review, see Martin, 2007). Moreover, manipulability could be a confounded factor when comparing natural (e.g., animals) and artifact (e.g., tools or household items) concepts. Filliter, McMullen, and Westwood (2005) demonstrated that when object domain and object manipulability were specifically dissociated, object identification speed depended on object manipulability. Thus, although object manipulability appears to be a decisive factor in adult conceptual processing, the distinction between manipulable and nonmanipulable objects has never been explored in research on conceptual development.

The present study was designed to test a distinction between manipulable and nonmanipulable object concepts in children. We investigated how children process perceptual/ visual and contextual/functional similarities for manipulable and nonmanipulable objects, both natural kinds and artifacts. We used basic-level taxonomic (e.g., jacketcoat) and thematic (e.g., jacket-hanger) relations between representations of real objects. These relations (1) are mainly based on perceptual similarity and contextual/ functional relations, (2) can be directly detected from the environment from an early age, and (3) concern all kinds of objects. We expected that children would be faster to process basic-level relations (perceptual/visual similarity) for nonmanipulable than for manipulable objects. Conversely, we assumed that children would be faster to process thematic relations (contextual/functional similarity) for manipulable than for nonmanipulable objects.

\section{METHOD}

\section{Participants}

In a developmental perspective, three age groups were considered. Thirty-six 5-year-old children $(M=5$ years, 6 months; $S D=$ 3 months; 22 girls and 14 boys) and thirty-six 7-year-old children ( $M=7$ years, 6 months; $S D=4$ months; 16 girls and 20 boys) participated in the study. The children were attending preschool and the second year of elementary school, respectively. Twenty adults $(M=$ 23 years, 6 months; $S D=7$ years, 2 months) were also recruited. They were psychology students from the Université Pierre MendèsFrance, and they received course credit for their participation.

\section{Materials}

Test stimuli were 100 black-and-white drawings, including 20 target pictures. Manipulability and domain were crossed between target pictures: Five represented manipulable artifacts (tools, kitchen utensils, and clothes), 5 manipulable natural objects (fruits, vegetables, plants, and body parts), 5 nonmanipulable artifacts (habitat, furniture, and vehicles), and 5 nonmanipulable natural objects (animals and human beings). Manipulable objects were objects that could be picked up or grasped with the hand in relation with their intended use. For each target picture (e.g., a jacket), 4 other pictures were selected. One was taxonomically related at the basic level (e.g., a coat) and one thematically related (e.g., a hanger); the other two were unrelated to the target picture (e.g., a stove and a hot-air balloon). Forty test triads, including a target picture, a related picture (either thematically or taxonomically related), and an unrelated picture were designed (see Figure 1 and the Appendix).

Control of perceptual similarity. Basic-level taxonomically related pictures were expected to be more visually similar than thematically related pictures. However, within each type of relation, perceptual similarity should be equivalent between the four object kinds (manipulable-nonmanipulable $\times$ artifact-natural). To ensure that this was the case, the 40 related picture pairs were presented 1 at a time to 20 additional adults who were instructed to rate on a 10-point scale for each pair to what extent the 2 pictures were visually similar. The ANOVA conducted on mean visual similarity scores with relation type, object manipulability, and object domain as between-items factors revealed only a main effect of relation type. Basic-level taxonomic relations $(M=6.6, S D=1.43)$ were more similar than were thematic relations $(M=2.2, S D=0.82)$ $[F(1,32)=144.5, p<.001]$.

Control of thematic associative strength. Thematically related pictures were designed to be highly associated at any age. In addition, the associative strength between the target pictures and their thematically related pictures should not differ between the four object kinds. A mean measure of associative strength for each thematic pair was obtained for each age group. Ten additional 5-year-olds, 7 -year-olds, and adults were presented the 20 critical thematic pairs with 20 fillers (more or less associated), 1 pair at a time. They were instructed to rate on a 10-point scale how strongly the two pictures were associated. For children, we used manual scales very similar to those used to measure pain intensity (McCaffery \& Beebe, 1993). Separate ANOVAs were conducted in each age group on the mean associative strength score, with object manipulability and object domain as between-items factors. No effect was significant, confirming that the associative strength between thematically related pictures was equivalent between object conditions. They were all highly associated (5-year-olds, $M=8.64, S D=1.24$; 7 -year-olds, $M=8.31, S D=1.20$; adults, $M=8.85, S D=0.085$ ).

The 40 triads were displayed in two series of 20 trials. Each target picture appeared twice, with a basic-level taxonomic associate in one list and with a thematic associate in the other. Eight additional triads were designed as practice trials.

\section{Procedure}

Triads were displayed on a computer monitor using the E-Prime software (Psychology Software Tools Inc., Pittsburgh, PA). Each trial began with a fixation point for $500 \mathrm{msec}$. It was immediately followed by the display of a triad composed of one target picture, one related picture, and one nonrelated picture. Each target picture appeared in the center of the top of the screen. The related and nonrelated pictures were presented in either the bottom left or the bottom right corner of the screen, their relative position being counterbalanced across trials. Participants were asked to decide "which one of

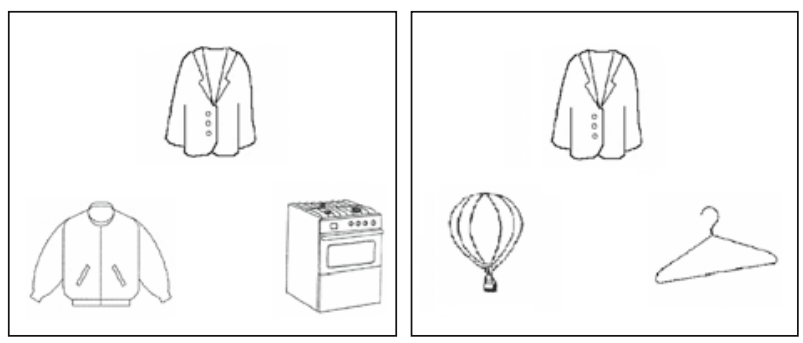

Figure 1. Example of a basic-level taxonomic triad (left) and a thematic triad (right) used for a same target picture; the two central pictures are unrelated to the target. 

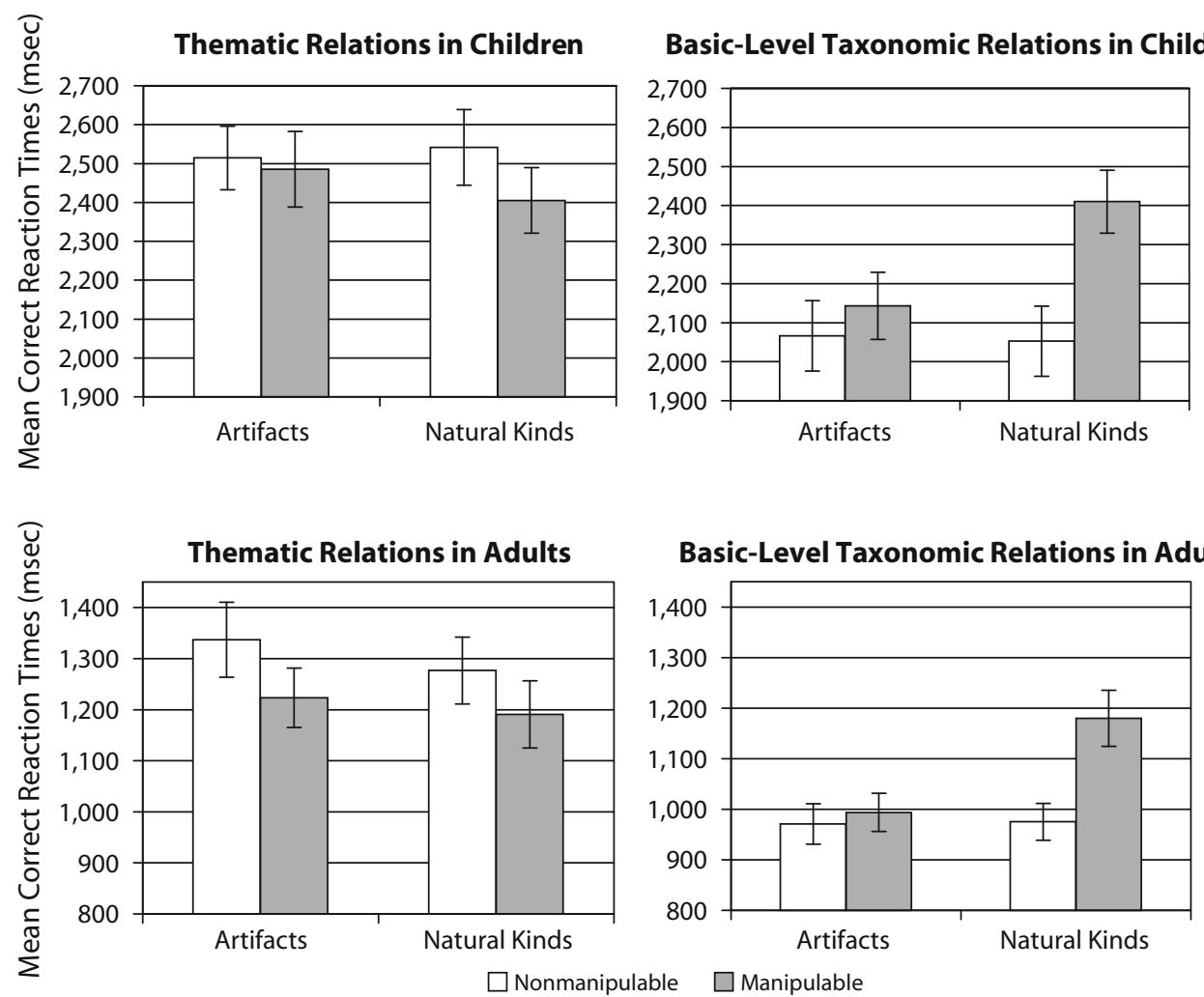

\section{Basic-Level Taxonomic Relations in Adults}

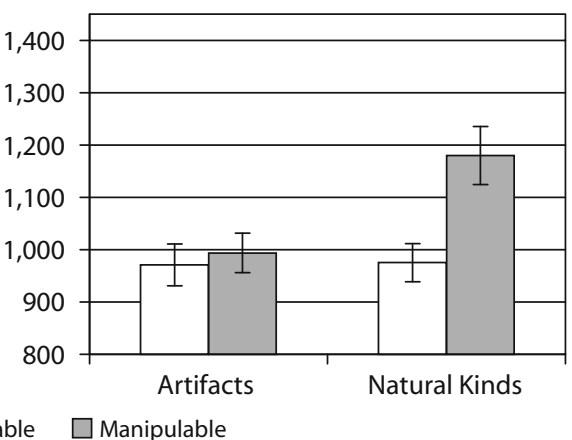

Figure 2. Means and standard errors of correct reaction times for children and adults according to relation type, concept manipulability, and domain.

the two bottom pictures goes with the target picture," using the two buttons of the response box. They were instructed to press the left button with their left index finger for the bottom left picture and the right button with their right index finger for the bottom right picture. They were told to respond as quickly and accurately as possible. Each triad was displayed until the participant responded. Each participant performed 8 practice trials and then performed the task with the two lists of 20 trials each. Children could have a break of a few minutes between lists to relax. The order of list presentation was counterbalanced across participants. RTs and accuracy were recorded for the 40 experimental trials.

\section{RESULTS}

Because the task was very easy for adults, and their RTs were consistently shorter than children's, separate statistical analyses were conducted. RTs that were more than $3 S D$ s above each participant's mean ( $1.5 \%$ of children's and adults' data), as well as RTs for incorrect responses ( $4.5 \%$ of children's data and $1.3 \%$ of adults' data) were excluded from the analysis. This trimming method led to the removal of $6 \%$ of the data at the most. Analysis on correct RTs was done after a logarithmic transformation. Normality of distributions and homogeneity of variances across conditions were thus respected. Results are reported in Figure 2.

\section{Analysis of Children's Performance}

A four-way ANOVA, with relation type (basic-level taxonomic, thematic), object manipulability (manipula- ble, nonmanipulable), and object domain (natural kinds, artifacts) as within-subjects factors, and age (5 and 7 years) as a between-subjects factor, was conducted on correct RTs. The main effects of age, relation type, object manipulability, and object domain were significant. Older children were faster than younger ones $[F(1,70)=57.57$, $p<.001]$. Moreover, a global advantage was observed for basic-level taxonomic relations $[F(1,70)=105, p<.001]$, for nonmanipulable objects $[F(1,70)=18.7, p<.001]$, and for natural kinds $[F(1,70)=5.37, p<.05]$. More importantly, the expected interaction between relation type and manipulability was significant $[F(1,70)=37.11, p<$ $.001]$. Planned comparisons revealed that children were faster to identify thematic relations for manipulable objects $(M=2,445 \mathrm{msec}, S D=770 \mathrm{msec})$ than for nonmanipulable objects $(M=2,527 \mathrm{msec}, S D=757 \mathrm{msec})$, whatever domain the objects belonged to $[F(1,70)=5.78$, $p<.05]$. On the contrary, children accessed basic-level taxonomic relations for nonmanipulable objects $(M=$ $2,059 \mathrm{msec}, S D=761 \mathrm{msec}$ ) more quickly than for manipulable objects $(M=2,276 \mathrm{msec}, S D=714 \mathrm{msec})$ $[F(1,70)=49.93, p<.001]$. Moreover, the interaction between relation type and object manipulability was modulated by domain of objects, as indicated by the three-way relation type $\times$ object manipulability $\times$ object domain interaction $[F(1,70)=8.24, p<.01]$. A Scheffé post hoc test revealed that for basic-level taxonomic relations, the disadvantage for manipulable objects was greater in the 
case of natural kinds $(p<.005)$. The pattern of results was similar between the 5- and 7-year-olds, since age did not interact with any of the within-subjects factors.

Concerning accuracy, mean error rate was relatively low $(M=6 \%)$, even in the youngest group $(M=9 \%)$. Nevertheless, to ensure that there was no speed-accuracy trade-off, a four-way ANOVA on accuracy performance was performed. Results show significant main effects of age and relation type consistent with RTs. A global advantage was observed for older children and for basic-level taxonomic relations. However, object manipulability did not influence accuracy. This result confirms the absence of speed-accuracy trade-off in children's performance.

\section{Analysis of Adults' Performance}

Since errors performed by adults were very rare $(M=$ $1.3 \%$ ), they were not analyzed. A three-way ANOVA with relation type (basic-level taxonomic, thematic), object manipulability (manipulable, nonmanipulable), and object domain (natural kinds, artifacts) as within-subjects factors conducted on correct RTs revealed effects similar to those in children. There was a main advantage for basiclevel taxonomic relations $[F(1,19)=120.3, p<.001]$. The predicted interaction between relation type and object manipulability was significant $[F(1,19)=60.57, p<$ $.001]$ and was modulated by object domain, as indicated by the three-way relation type $\times$ object manipulability $\times$ object domain interaction $[F(1,19)=9.33, p<.01]$. Like children, adults identified thematic relations faster for manipulable $(M=1,207 \mathrm{msec}, S D=274 \mathrm{msec})$ than for nonmanipulable $(M=1,307 \mathrm{msec}, S D=309 \mathrm{msec})$ objects $[F(1,19)=16.64, p<.001]$. They also identified basiclevel taxonomic relations faster for nonmanipulable $(M=$ $973 \mathrm{msec}, S D=169 \mathrm{msec})$ than for manipulable $(M=$ $1,087 \mathrm{msec}, S D=230 \mathrm{msec})$ objects $[F(1,19)=61.68$, $p<.001]$; again, this difference was greater for natural objects, as indicated by a Scheffé post hoc test $(p<.005)$.

\section{DISCUSSION}

The present findings provide initial evidence for the influence of object manipulability on children's conceptual processing. Five- and 7-year-old children, like adults, processed perceptual similarity and contextual/functional relations differently for manipulable and nonmanipulable object concepts.

Thematic relations processing was faster for manipulable than for nonmanipulable objects independently of domain (natural kinds or artifacts). Thematic relations (e.g., spoon-yoghurt) are based on contextual and functional relations between objects that can be easily detected from interactions with objects in daily action schemas (Borghi \& Caramelli, 2003; Mandler, 2000; Nelson, 1983). Therefore, thematic relations appear to be more rapidly identified for objects that particularly induce action and use experience-namely, manipulable objects. This result suggests that the formation of manipulable object concepts may recruit a particular mechanism, in which action and use would play a key role. Action experience involvement has been largely described in adult processing of manipulable object concepts (Borghi, Bonfiglioli, Lugli, et al., 2007; Bub, Masson, \& Bukach, 2003; Myung et al., 2006; Tucker \& Ellis, 2004). The present findings go further by highlighting the role of action in the development of manipulable object concepts as early as age 5 .

The opposite pattern was observed concerning basiclevel taxonomic relations. They were processed faster for nonmanipulable than for manipulable objects by both the children and the adults. Basic-level taxonomic relations are characterized mainly by perceptual similarity relations. This suggests that the formation of nonmanipulable object concepts would particularly rely on visual similarity between objects. This finding is consistent with neuroimagery data that show a specific involvement of the visual cerebral areas when processing nonmanipulable object concepts, such as animals (Martin, 2007). Moreover, the manipulable/nonmanipulable difference was stronger for natural kinds than for artifacts. Basic-level taxonomic processing of natural manipulable objects (i.e., fruit and vegetables, body parts) was particularly slow. It could be that visual similarity relations may be specifically difficult to process when two conditions are combined: (1) The perceptual structure of objects is not the most crucial information (manipulable objects), and (2) the perceptual structure could not be easily derived from functional information (natural kinds). Concerning artifacts, studies in children (Ahn, 1998; Ahn et al., 2000) and adults (Tyler $\&$ Moss, 2001) revealed that artifact functional properties usually determine their superficial features. The strong link between the structure and the function of artifacts may have facilitated the identification of basic-level taxonomic relations between artifacts, either manipulable or nonmanipulable. As recently developed by Chaigneau, Barsalou, and Sloman (2004), function seems to be a complex relational system that links several types of information, such as physical structure and action. Further investigations would be required to specify the functional relational system of different object kinds.

We found a distinction in children's processing of manipulable and nonmanipulable object concepts from age 5. Previous studies in children have already shown that perceptual similarity and contextual/functional relations underlie conceptual development (Bonthoux \& Kalénine, 2007; Borghi \& Caramelli, 2003; Diesendruck \& Bloom, 2003; DiYanni \& Kelemen, 2005; Kemler Nelson, Frankenfield, Morris, \& Blair, 2000; Nelson, 1983; Quinn \& Eimas, 2000; Sloutsky et al., 2007). The present study further demonstrates that, for children from age 5, perceptual and contextual/functional information is accessible differently for manipulable and nonmanipulable object concepts. The fact that an object is liable to be manipulated may either facilitate (thematic relations) or interfere with (basic-level taxonomic relations) conceptual processing. This hypothesis was recently tested by Borghi, Bonfiglioli, Ricciardelli, Rubichi, and Nicoletti (2007). They observed that participants categorized manipulable objects faster than they did nonmanipulable objects when manipulability was relevant for the conceptual task ("Could objects be picked up and put inside a backpack?"). In contrast, object manipulability interfered with conceptual processing when it was not relevant for the task ("Are 
objects natural kinds or artifacts?"). The type of interaction with objects - namely, the possibility of manipulating them or not - may be decisive when processing conceptual relations. In addition, the influence of the manipulability factor in children's conceptual processing suggests that some aspects of their sensorimotor experience may be involved in concept formation. This hypothesis fits into the general framework of embodied views of concepts (e.g., Barsalou, 2008), which has already received important support from studies in adults. A major issue remains how and to what extent concepts are shaped by children's sensorimotor experience with objects.

\section{AUTHOR NOTE}

Correspondence concerning this article should be addressed to S. Kalénine, Laboratoire de Psychologie et NeuroCognition, Université Pierre Mendès-France, CNRS UMR 5105, P.O. Box 47, F-38040 Grenoble Cedex 9, France (e-mail: solene.kalenine@upmf-grenoble.fr).

\section{REFERENCES}

AHN, W.-K. (1998). Why are different features central for natural kinds and artifacts? The role of causal status in determining feature centrality. Cognition, 69, 135-178.

Ahn, W.-K., Gelman, S. A., Amsterlaw, J. A., Hohenstein, J., \& KALISH, C. W. (2000). Causal status effect in children's categorization. Cognition, 76, B35-B43.

Barsalou, L. W. (1999). Perceptual symbol systems. Behavioral \& Brain Sciences, 22, 577-660.

Barsalou, L. W. (2008). Grounded cognition. Annual Review of Psychology, 59, 617-645.

Bonthoux, F., \& KalÉnine, S. (2007). Preschoolers' superordinate taxonomic categorization as a function of visual vs. contextual/functional information and object domain. Cognition, Brain, Behaviour, 11, 713-731.

Borghi, A. M. (2004). Object concepts and action: Extracting affordances from objects parts. Acta Psychologica, 115, 69-96.

Borghi, A. M., Bonfiglioli, C., Lugli, L., Ricciardelli, P., RuBICHI, S., \& Nicoletti, R. (2007). Are visual stimuli sufficient to evoke motor information? Studies with hand primes. Neuroscience Letters, 411, 17-21.

Borghi, A. M., Bonfiglioli, C., Ricciardelli, P., Rubichi, S., \& NiCOLETti, R. (2007). Do we access object manipulability while we categorize? Evidence from reaction time studies. In A. C. Schalley \& D. Khlentzos (Eds.), Mental states: Vol. 1. Evolution, function, nature (pp. 153-170). Philadelphia: John Benjamins.

Borghi, A. M., \& CARAmelli, N. (2003). Situation bounded conceptual organization in children: From action to spatial relations. Cognitive Development, 18, 49-60.

Bub, D. N., Masson, M. E. J., \& BuKach, C. M. (2003). Gesturing and naming: The use of functional knowledge in object identification. Psychological Science, 14, 467-472.

Capitani, E., Laiacona, M., Mahon, B., \& Caramazza, A. (2003). What are the facts of semantic category-specific deficits? A critical review of the clinical evidence. Cognitive Neuropsychology, 20, 213-261.

Casler, K., \& Kelemen, D. (2007). Reasoning about artifacts at 24 months: The developing teleo-functional stance. Cognition, 103, 120-130.

Chaigneau, S. E., Barsalou, L. W., \& Sloman, S. A. (2004). Assessing the causal structure of function. Journal of Experimental Psychology: General, 133, 601-625.

ChaO, L. L., \& Martin, A. (2000). Representation of manipulable manmade objects in the dorsal stream. Neurolmage, 12, 478-484.

Cree, G. S., \& McRAE, K. (2003). Analyzing the factors underlying the structure and computation of the meaning of chipmunk, cherry, chisel, cheese, and cello (and many other such concrete nouns). Journal of Experimental Psychology: General, 132, 163-201.

Diesendruck, G., \& Bloom, P. (2003). How specific is the shape bias? Child Development, 74, 168-178.

Diesendruck, G., Hammer, R., \& Catz, O. (2003). Mapping the simi- larity space of children and adults' artifact categories. Cognitive Development, 18, 217-231.

Diesendruck, G., Markson, L., \& Bloom, P. (2003). Children's reliance on creator's intent in extending names for artifacts. Psychological Science, 14, 164-168.

DiYanni, C., \& Kelemen, D. (2005). Time to get a new mountain? The role of function in children's conceptions of natural kinds. Cognition, 97, 327-335.

Filliter, J. H., McMullen, P. A., \& Westwood, D. (2005). Manipulability and living/non-living category effects on object identification. Brain \& Cognition, 57, 61-65.

Gerlach, C., Law, I., \& Paulson, O. B. (2002). When action turns into words. Activation of motor-based knowledge during categorization of manipulable objects. Journal of Cognitive Neuroscience, 14, 1230-1239.

Hughes, D., Woodcock, J., \& Funnell, E. (2005). Conceptions of objects across categories: Childhood patterns resemble those of adults. British Journal of Psychology, 96, 1-19.

Kelemen, D., \& DiYanni, C. (2005). Intuitions about origins: Purpose and intelligent design in children's reasoning about nature. Journal of Cognition \& Development, 6, 3-31.

Kellenbach, M. L., Brett, M., \& Patterson, K. (2003). Actions speak louder than functions: The importance of manipulability and action in tool representation. Journal of Cognitive Neuroscience, 15, 30-46.

Kemler Nelson, D. G., Chan Egan, L., \& Holt, M. B. (2004). When children ask, "what is it?" What do they want to know about artifacts? Psychological Science, 15, 384-389.

Kemler Nelson, D. G., Frankenfield, A., Morris, C., \& Blair, E. (2000). Young children's use of functional information to categorize artifacts: Three factors that matter. Cognition, 77, 133-168.

Kemler Nelson, D. G., Russell, R., Duke, N., \& Jones, K. (2000). Two-year-olds will name artifacts by their functions. Child Development, 71, 1271-1288.

Mandler, J. M. (2000). Perceptual and conceptual processes in infancy. Journal of Cognition \& Development, 1, 3-36.

Marques, J. F. (2006). Specialization and semantic organization: Evidence for multiple semantics linked to sensory modalities. Memory \& Cognition, 34, 60-67.

Martin, A. (2007). The representation of object concepts in the brain. Annual Review of Psychology, 58, 25-45.

McCAFFERy, M., \& BeEBe, A. (1993). Pain: Clinical manual for nursing practice. Baltimore: Mosby.

Mcrae, K., Cree, G. S., Seidenberg, M. S., \& McNorgan, C. (2005). Semantic feature production norms for a large set of living and nonliving things. Behavior Research Methods, 37, 547-559.

Mounoud, P., Duscherer, K., Moy, G., \& Perraudin, S. (2007). The influence of action perception on object recognition: A developmental study. Developmental Science, 10, 836-852.

Myung, J.-Y., Blumstein, S. E., \& Sedivy, J. C. (2006). Playing on the typewriter, typing on the piano: Manipulation knowledge of objects. Cognition, 98, 223-243.

Nelson, K. (1983). The derivation of concepts and categories from event representations. In E. K. Scholnick (Ed.), New trends in conceptual representation: Challenges to Piaget's theory? (pp. 129-149). Hillsdale, NJ: Erlbaum.

Pecher, D., Zeelenberg, R., \& Barsalou, L. W. (2003). Verifying different-modality properties for concepts produces switching costs. Psychological Science, 14, 119-124.

Pecher, D., Zeelenberg, R., \& Barsalou, L. W. (2004). Sensorimotor simulations underlie conceptual representations: Modality-specific effects of prior activation. Psychonomic Bulletin \& Review, 11, 164-167.

QuinN, P. C., \& EIMAs, P. D. (2000). The emergence of category representations during infancy: Are separate perceptual and conceptual processes required? Journal of Cognition \& Development, 1, 55-61.

Sloutsky, V. M., Kloos, H., \& Fisher, A. V. (2007). When looks are everything: Appearance similarity versus kind information in early induction. Psychological Science, 18, 179-185.

Sloutsky, V. M., \& SPINO, M. A. (2004). Naive theory and transfer of learning: When less is more and more is less. Psychonomic Bulletin \& Review, 11, 528-535.

StANFiELD, R. A., \& ZWAAN, R. A. (2001). The effect of implied orientation derived from verbal context on picture recognition. Psychological Science, 12, 153-156. 
Truxaw, D., Krasnow, M. M., Woods, C., \& German, T. P. (2006). Conditions under which function information attenuates name extension via shape. Psychological Science, 17, 367-371.

Tucker, M., \& Ellis, R. (2004). Action priming by briefly presented objects. Acta Psychologica, 116, 185-203.
TYLER, L. K., \& Moss, H. (2001). Towards a distributed account of conceptual knowledge. Trends in Cognitive Sciences, 5, 244-252.

ZwaAn, R. A., Stanfield, R. A., \& Yaxley, R. H. (2002). Language comprehenders mentally represent the shapes of objects. Psychological Science, 13, 168-171.

\section{APPENDIX}

Complete List of the 40 Thematic and Basic-Level Taxonomic Triads

\begin{tabular}{|c|c|c|}
\hline \multicolumn{3}{|c|}{ raxomomic mads } \\
\hline Target & Related Picture & Nonrelated Picture \\
\hline \multicolumn{3}{|c|}{ Thematic Triads } \\
\hline castle & knight & bulb \\
\hline washbasin & soap & princess \\
\hline cupboard & pullover & wolf \\
\hline armchair & television & hamster \\
\hline bus & schoolchild & carafe \\
\hline screwdriver & screw & crocodile \\
\hline spoon & yoghurt & stairs \\
\hline pan & potato & glasses \\
\hline jacket & hanger & hot-air balloon \\
\hline glove & toboggan & swan \\
\hline $\operatorname{dog}$ & bone & mountain \\
\hline squirrel & hazelnuts & clothes peg \\
\hline goat & shepherd & helicopter \\
\hline mosquito & bite on hand skin & apricot \\
\hline baby & feeding bottle & nut \\
\hline egg & bird & boat \\
\hline orange & bottle of juice & pig \\
\hline open hand & pen & ruler \\
\hline plant & pot & bat \\
\hline tulip & vase & spider \\
\hline \multicolumn{3}{|c|}{ Basic-Level Taxonomic Triads } \\
\hline castle & different castle & dustbin \\
\hline washbasin & $\operatorname{sink}$ & tamer \\
\hline cupboard & chest of drawers & snake \\
\hline armchair & sofa & whale \\
\hline bus & different bus & phone \\
\hline screwdriver & different screwdriver & shark \\
\hline spoon & different spoon & barrier \\
\hline pan & different pan & match \\
\hline jacket & coat & stove \\
\hline glove & mitten & octopus \\
\hline $\operatorname{dog}$ & different dog & cactus \\
\hline squirrel & different squirrel & comb \\
\hline goat & different goat & crane \\
\hline mosquito & fly & corn \\
\hline baby & different baby & peach \\
\hline egg & eggs & church \\
\hline orange & different orange & peacock \\
\hline open hand & fist & belt \\
\hline plant & different plant & $\mathrm{crab}$ \\
\hline tulip & red poppy & elephant \\
\hline
\end{tabular}

(Manuscript received July 23, 2007;

revision accepted for publication January 7, 2008.) 